\title{
Andreas Wittel:
}

\section{Qualities of Sharing and their Transformations in the Digital Age}

\begin{abstract}
:
This article examines the social side of sharing. It is an attempt to work towards a sociological concept of sharing in the digital age. This is the hypothesis: different forms of sharing have different qualities with respect to the social. Digital technologies bring about new forms of sharing. In order to support this claim I will analyse the social qualities of sharing by focusing on the object, on what is being shared. Using an object-centred analysis it will be argued that digital forms of sharing introduce a new function of sharing. Whereas pre-digital sharing was about exchange, sharing with digital technologies is about exchange and about distribution.
\end{abstract}

\section{Agenda:}

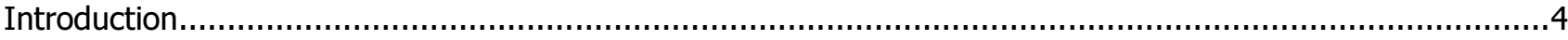

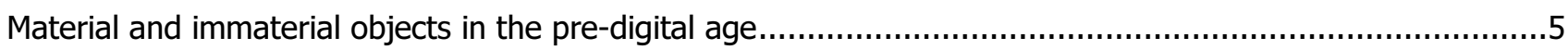

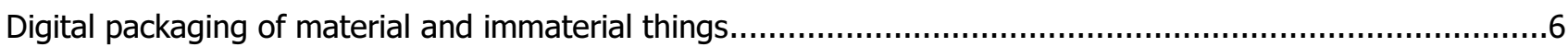

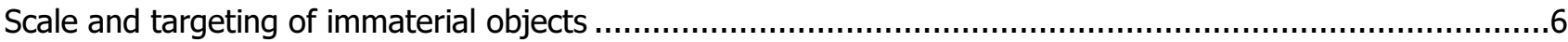

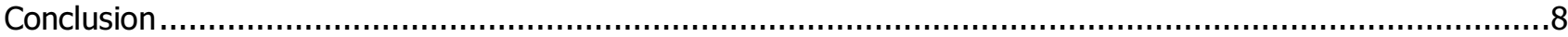

\section{Author:}

Dr. Andreas Wittel

- School of Arts and Humanities, Nottingham Trent University, Clifton Lane, Nottingham NG11 8NS, UK.

- + 44 - 115 - 8486115, andreas.wittel@gmail.com

- Relevant publications:

- Enthusiasm as affective labour: On the productivity of enthusiasm in the media industry (with G. Bachmann). M/C Journal 12/2 (2009).

- Medienethnographie (with G. Bachmann). In: R.Ayass and J. Bergmann, Qualitative Methoden der Mediensoziologie. Reinbek: Rowohlt Taschenbuch Verlag, p.183-219 (2006).

- Culture, labour and subjectivity: for a political economy from below. Capital and Class No 84. Special Issue, Creative Industries: Production, Consumption and Resistance. J. Shorthose and G. Strange (eds.) pp. 11-30 (2004).

- Toward a network sociality. Theory, Culture \& Society 18(6): 51-76 (2001).

- Ethnography on the move: from field to net to internet. Forum Qualitative Social Research (Online journal) 1(1) (2000).

- Belegschaftskultur im Schatten der Firmenideologie. Eine ethnographische Fallstudie. Berlin: Sigma (1997) 


\section{Introduction}

Sharing is a rather mundane everyday practice, usually associated with family, kinship, friendship, and community. However the notion of sharing has recently received much attention in conversations on digital media and network cultures. Now sharing is anything but mundane. It is an expression of a utopian imaginary. Sharing now is associated with politics, with socialist, communist, and anarchist values, with the free culture movement and the digital commons. Along with similar values such as openness and collaboration it stands against everything that is associated with neo-liberal ethics (this despite business writers' attempts to co-opt such terms for their own profitable purposes). Indeed, the politics of appraisals for sharing vary greatly.

No doubt, as Benkler (2004) has suggested, sharing (at least when it isn't being mystified) is 'nice'. But a closer look suggests that the matter of sharing is more complicated than this. Apart from the term 'sharing' itself, St. Martin's cutting of his coat in two halves to help a freezing homeless person has nothing in common with the sharing of a house, which again is a rather different social practice than the uploading of our family photos on social media platforms.

It is the rather neglected social aspects of sharing that are at the centre of the following considerations. So far most commentators have addressed the economic implication of sharing in the digital age, sometimes with a reference to gift economies (Benkler 2004; Benkler 2006; Leadbeater 2008; Tapscott/Williams 2008; Shirky 2010). Usually it is assumed that all forms of sharing strengthen the social. This implicit assumption needs to be contested - particularly with respect to digital environments. In order to do so, we have to unpack a term which is becoming more complex. 'Sharing' is used for different social practices with different functions and different motivations. It is used for a multitude of social and ethical realities. There is a danger of conflating different social qualities of sharing, which in turn may produce distortions, illusions, and delusions.

Let's illustrate the difference between an economic and a social analysis of sharing with an example. Yochai Benkler (2004) has developed both an ambitious and influential analysis of sharing in the networked economy. Using the two examples of carpooling and distributed computing (e.g. SETI@home) Benkler demonstrates that 'social sharing' is a significant modality of economic pro- duction that co-exists and sometimes outperforms price-based systems of economic production. The significance of Benkler's work lies in two things. Firstly, he does not restrict his analysis to creative labour and its products such as knowledge, information and ideas. Instead he focuses on rival goods as well. Secondly, he argues from an object perspective. He goes to great length to carve out the features of 'shareable goods'. Shareable goods are those that have excess capacities (unused seats in a car and unused computing power). With this analysis of shareable goods he can explain why some goods which are shared can outperform a system where the same goods are regulated through markets and price-based systems.

What makes perfect sense for an economic analysis is rather problematic for a social analysis of sharing. From a social perspective the idea of 'shareable goods' is nonsensical, as all goods are potentially shareable. Whether a car has excess capacities does not depend on some objective economic reasoning (number of spare seats available), but on the willingness of those who are sitting in the car to share. Shareability as a social category is not defined by some intrinsic qualities of goods but by human beings and their subjective reasoning. Nevertheless it is indeed interesting for a social analysis of sharing to focus on the shared object - not to gain insights on shareability (as does Benkler with his economic perspective) but, as I want to argue, to make claims about the social qualities of sharing.

This opens up a second point of departure. Whereas Benkler's analysis of 'shareable goods' does not differentiate between rival and non-rival goods, this distinction as well as the difference between bits and atoms is rather crucial for an understanding of the social side of sharing. Let's illustrate this point with his treatment of carpooling as equivalent to distributed computing. For Benkler both are examples of 'social sharing'. What works with respect to the realm of economy does not work with respect to the realm of the social. To put it bluntly, carpooling produces the social, it produces social processes, social proximity, and quite likely some form of interaction, maybe even conflicts and/or social bonds. Distributed computing - even though this is a project of immense economic, environmental, and ethical value - produces nothing but computing power.

As already indicated the aim of this article is an attempt to work towards a sociological concept of sharing in the digital age. Whilst there is a huge body of theoretical work on the gift, particularly 
within anthropology (Mauss 1954; Sahlins 1974; Bourdieu 1997; Godelier 1999: Graeber 2002; Hyde 2007) practices of sharing are surprisingly underresearched. This lack of groundbreaking conceptual work on sharing can partially be explained with a subsumption of some forms of sharing (e.g. the sharing of food) under the notion of gift exchange. It could also result from the fact that the notion of sharing means too many different things. The following considerations are not a comprehensive analysis of sharing. The frame is rather narrow: an inspection of the impact which digital technologies have on the social qualities of sharing.

This is the hypothesis: different forms of sharing have different qualities with respect to the social. They have different levels of impact on the realm of the social. Those forms of sharing that intensify social interaction are of a higher quality than forms of sharing which do not strengthen social ties. I am inspired by Benkler's focus on objects (in his case 'goods'), however I am not studying economic shareability but social qualities of sharing. In a predigital world such an inspection of different qualities would not have made much sense, as all things that were shared (material things as well as immaterial things such as thoughts or affects) led to an intensification of social interaction. In the digital age however this is not a foregone conclusion. Digital technologies, I will argue, bring about new forms of sharing - however these new forms may not per se enrich the social.

In order to establish a framework for an analysis of qualities of sharing I will focus on the object, on what is being shared. To unpack the object, we need to consider three points: (1) We need to distinguish between material and immaterial things in the pre-digital age. (2) We need to examine the digital packaging of material and immaterial things. Here we will apply Bruno Latour's distinction between mediators and intermediaries to explain how digital objects are being shared. (3) We need to address issues such as scale and targeting and study their implications for the creation of social bonds in digital environments.

\section{Material and immaterial objects in the pre-digital age}

Let us put digital technologies aside for a moment. In the pre-digital age people shared material and immaterial things. Material things being shared become 'reduced'for those who engage in the act of sharing. This observation applies to both, material objects such as T-Shirts, vinyl record albums, and newspapers and materially enclosed spaces such as houses, cars and office rooms. It also applies to biological things. If an apple is shared between two people, they will each get only half of the apple. The motivations for the sharing of material and biological things may differ greatly. Someone may prefer to live alone and still share a house for economic reasons. Another person may choose to share a house for purely social reasons. Irrespectively of these different motivations the decision to share will generally produce an intensification of social activity and social exchange. Two friends who decide to buy a vinyl record together will not have full control over this material object and will have to negotiate terms of usage (the album gets reduced for each of them). But the purchase does strengthen their bond as the album creates an additional link between them.

Whereas the sharing of material things produces the social (as a consequence), the sharing of immaterial things is social in the first place. Whether we share intellectual things such as thoughts, knowledge, information, ideas, and concepts, or affective things such as feelings, memories, experiences, taste, and emotions, the practice of sharing is a social interaction. ${ }^{1}$ The sharing of immaterial things produces (as a consequence) other things than social relationships, such as knowledge, art, rules, and religion.

Whereas the sharing of material things can require some forms of sacrifice for those who share (only one person can wear a shared T-Shirt at any given time), the sharing of immaterial things does not 'reduce' anything but adds value to whatever is being exchanged. This is very obvious for intellectual exchanges, but it is also true for affective exchanges. 'A joy shared is a joy doubled, a trouble shared is a trouble halved', so the proverb goes.

To summarise: In the pre-digital age sharing is always mutual, always social, and always based on the principle of generalised reciprocity. ${ }^{2}$

\footnotetext{
${ }^{1}$ For the distinction between intellectual and affective things
within the realm of the immaterial see Hardt/Negri (2000:

For the distinction between intellectual and affective things
within the realm of the immaterial see Hardt/Negri (2000: 290-293)
}

One might object to this claim and point toward altruistic practices of selfless giving, such as blood donations, organ donations, financial donations for good causes, and collections of old clothes for people in need. It is of course correct that these practices are non-reciprocal, with no intention for exchange. However I would not subsume these practices un- 


\section{Digital packaging of material and immaterial things}

What happens to the examples mentioned above when they are being shared digitally? If we disregard for a moment the issue of scale, the social quality of sharing does not change systematically when immaterial things such as ideas or feelings are being shared digitally. A personal conversation between two friends or a professional exchange between two scientists may happen face-to-face, via letters, on the telephone, in an online chat-room or with instant text messaging. Pace McLuhan, neither the mediation of these conversations in general, nor the specific medium being chosen necessarily have a systematic effect on the social bonds that are produced through these exchanges. We would assume that media-literate people would pick whatever medium they see appropriate and purpose-fit for the nature of their conversation.

How about material things? Obviously not all material things can be shared digitally, think of a table. What can be shared are those material objects than contain immaterial/cultural content. a book, a newspaper, a record album, a photo album. Before the digital age cultural/immaterial content - a novel, a song, a film - was produced and reproduced with materials such as paper, audiotape and videotape. Now this material packaging of cultural/immaterial content can be replaced or expanded with digital packaging, with bits instead of atoms.

I want to argue that this new format, the digital packaging of immaterial content has profound implications for the notion of sharing. What really is changing is the notion of sharing itself, and the associated 'reduction' of shared objects. Sharing a car means not having access to the car all the time, sharing a mango with someone else means that both can only eat half of the mango. This form of sharing usually involves the notion of sacrifice and economic anthropology went to great length to argue that it is precisely this sacrifice that produces an intensification of social relationships, a strengthening of social ties.

The sharing of digital things is effortless, it does not involve any sacrifice. Digital things just get multiplied. If we share a poem digitally we do share it in an abstract way, we share the cultural/immaterial content, the meaning of the poem, we share our taste in poetry and literature, but we do not share the file itself.

der the notion of sharing. 'Giving' and 'giving away' would be more aapropriate terms for such altruistic gifts.
For this reason one could argue that the term sharing is rather problematic, perhaps misleading, for digital objects. It seems that sharing, like stealing, has entered the language of digital cultures due to mere ideological reasons. Both terms are used to justify new forms of social practices morally. Sharing is good, stealing is bad. But copying is neither good nor bad. Copying is neither sharing nor stealing, it is just copying, multiplying.

With respect to 'sharing' in the digital realm and its implications for social interaction we can differentiate between two forms of 'sharing', which draws on a distinction by Bruno Latour (2005), between intermediaries and mediators. Intermediaries transport messages (content, code, meaning) without transforming them. Mediators transform, translate, distort, and modify the meaning or the elements they are supposed to carry.

These concepts point toward different functions of digital sharing. Sharing as intermediary is about distribution, it refers to a pure dissemination of content (e.g. file-'sharing'). Sharing as mediator refers to, say mailing lists, wiki pages, discussion groups, blogs with feedback features etc. This is about exchange, or more precisely, about social exchange. It is about creation and production, and obviously this function of sharing has always existed; it is not at all specific to the digital age.

What is the relation between these two functions and the social qualities of sharing? In short, sharing as distribution has the potential to create social interaction but it also has the potential to not trigger any social responses. Distribution can turn into social exchange but there is no guarantee. Filesharing software, which more precisely should be called file-multiplication software, does not produce meaningful social exchanges. A blog or an entry in a social media platform starts as distribution but has the potential to turn into social exchange.

\section{Scale and targeting of immaterial objects}

The last part of this object-centred analysis focuses on immaterial things such as knowledge, ideas, passions and feelings. In particular we will focus on the difference between the digital and the nondigital sharing of immaterial things. To understand these differences we will have to examine the issue of scale and the issue of selection or targeting. Recently Charles Leadbeater (2008) coined a rather 
intriguing phrase: 'You are what you share'. There is something very beautiful about this statement, but it is also misleading as it suggests that the more we share the better we are. The reality however is rather different. Nobody can share everything with everybody. On the contrary, in our daily life we have to think carefully with whom we share and what we share. Sharing is an investment, so we are likely to select those who we consider to be trustworthy, those who we hope to respond to whatever we share in an appropriate way. Sharing also depends on timing, on the right moment. It depends on context and situation.

The first fundamental transformation digital technologies can have on the practice of sharing is the possibility of large-scale sharing. Rather than sharing with one person or a small group we use wikis, blogs, mailing-lists, social media sites to share intellectual and affective matters. These forms of large-scale sharing illustrate particularly well the blurring of the two functions of sharing, of distribution and social exchange. A new blog post is a onesided distribution of content into cyberspace. Real sharing as exchange only happens when the blog post receives comments in return.

The second fundamental way in which digital technologies can transform the sharing of immaterial things refers to selection and targeting. With largescale forms of sharing we abandon the possibility to select specific people we want to share with. Ultimately we cannot control who responds to what we distribute on wikis, blogs, social media sites, and mailing-lists. Instead of us choosing who we share with we get chosen by others for intellectual and affective exchanges. We also lose control over timing and the right moment to share something.

Large-scale digital sharing of knowledge and affect brings about new opportunities and advantages, but also new risks. The advantages and opportunities are very much visible in the realm of intellectual exchanges. The open-source movement, wikipedia, wikiversity, the A2K movement (Access to knowledge), social bookmarking, open education resources, open publishing - all these initiatives and many more have emerged with the rise of the social web, with the rise of peer production and mass collaboration. Large-scale digital sharing of knowledge, information, code and data is an incredible success story and has rightly been celebrated by a number of commentators over the last few years (Rheingold 2002; Weber 2004; von Hippel 2005; Benkler 2006; Tapscott/Williams 2008; Reagle 2010; Krikorian/Kapczynski 2010). It is by now a well known and well rehearsed argument that these forms of sharing have driven innovation to new levels and have produced an always growing (if always imperilled) digital knowledge commons.

Large scale sharing of affective matters has not yet turned into a success story to be celebrated. This form of sharing has not received the same attention and is less explored. It seems difficult here to make general arguments. This is a new phenomenon, which calls for more ethnographic research. In 'Alone Together' Sherry Turkle's (2011) tone as well as her assessment of virtual life is much more sober than in the first two books of her trilogy. Now there is a real danger that digital technology does not enhance the social but replace it. Eventually Turkle remains still cautiously optimistic, yet her stories of life in the age of social media are full of neglect, distraction, and meaningless practices of (dis)engagement.

It might be dangerous to equate large-scale sharing of affective matters with social media web sites only as there is a difference between blogs, and discussion groups on the one hand and social media platforms on the other hand. There is a difference with respect to anonymity (which is so far impossible to secure in social media sites) but also with respect to targeting (generally blogs, mailing lists and discussion groups are better suited for a specific community with similar interests than the rather diverse group of 'friends' and 'followers' we accumulate on social media sites. Thus the notion of sharing seems to be especially problematic in social media sites.

A very sad example of the social implications of large-scale sharing of affective matters can be found in a story published by the Telegraph in January $2011 .^{3}$ A 42 year old woman in the UK posted a message on Facebook to her 1,048 friends on Christmas day, announcing that she will commit suicide and that she has just swallowed the pills. Her message was widely discussed in her network and led to 148 responses where her 'friends' discussed the statement and the former breakdown of this women's relationship. But nobody bothered to call her, call the police, or go over to her place, even though many of her 'friends' discussing her post lived very local. So she died.

It's common sense that people who announce suicide want to be rescued. This is probably even 
more true in this specific incidence as the woman announced her suicide using large-scale sharing methods. It is not far fetched to assume that this woman would still be alive had she shared her intentions not on a digital network (with no possibility for selection and targeting) but with only one or more selected friends (no matter the media). Surely this is not a typical example from everyday life, it is not representative in any way. It does make clear however that Turkle has a point and that 1,048 Facebook-friends are not at all an indication for a rich social life. It also supports the argument I have been trying to make in this essay, that sharing as distribution should not be confused with sharing as social exchange. However, as this case sadly illustrates, this confusion can be all too real.

\section{Conclusion}

Definitions and meanings of words are not set in stone. They change over time and so does the term 'sharing'. Whereas sharing in the pre-digital age was meant to produce social exchange, sharing in the digital age is about social exchange on the one hand and about distribution and dissemination on the other hand. What makes sharing with digital media so hard to understand is exactly this blurring of two rather different purposes. To resist mystifications and ideological forms of hijacking of this word it is important to be aware of its multiple digital transformations.

\section{References}

Benkler, Y., 2004. Sharing nicely: on shareable goods and the emergence of sharing as a modality of economic production. Yale Law Journal, 114, pp.273-358.

Benkler, $Y ., 2006$. The wealth of networks: how social production transforms markets and freedom, New Haven and London: Yale University Press.

Bourdieu, P., 1997. Marginalia--some additional notes on the gift. In: A. Schrift, The logic of the gift: Toward an ethic of generosity. New York: Routledge, pp. 231-241.

Godelier, M., 1999. The enigma of the gift, Chicago: University of Chicago Press.

Graeber, D., 2002. Towards an anthropological theory of value: the false coin of our own dreams, Palgrave Macmillan.

Hardt, M. \& Negri, A., 2000. Empire, Cambridge, MA and London: Harvard University Press.
Hyde, L., 2007. The gift: how the creative spirit transforms the world, Canongate Books Ltd.

Krikorian, G. \& Kapczynski, A., 2010. Access to knowledge in the age of intellectual property, Cambridge (MA): MIT Press.

Latour, B., 2005. Reassembling the social: an introduction to actor-network-theory, Oxford: Oxford University Press.

Leadbeater, C., 2008. We-think: mass innovation, not mass production: the power of mass creativity, London: Profile Books.

Mauss, M., 1954. The gift: forms and functions of exchange in archaic societies, Cohen \& West Ltd.

Reagle, J.M., 2010. Good faith collaboration: the culture of Wikipedia, Cambridge, MA: MIT Press.

Rheingold, H., 2002. Smart mobs: the next social revolution. New York: Basic Books.

Sahlins, M., 1974. Stone age economics, London: Tavistock Publications Ltd.

Shirky, C., 2010. Cognitive surplus: creativity and generosity in a connected age, Allen Lane.

Tapscott, D. \& Williams, A.D., 2008. Wikinomics: how mass collaboration changes everything, Portfolio.

Turkle, S., 2011. Alone together: Why we expect more from technology and less from each other. New York: Basic Books.

von Hippel, E., 2005. Democratizing innovation, Cambridge, MA and London: MIT Press.

Weber, S., 2004. The success of open source, Cambridge, MA and London: Harvard University Press. i-r-i-e.net 